\title{
The Complexity of the Resurgence of Childhood Vaccine- Preventable Diseases in the United States
}

\author{
Ruth Lynfield • Robert S. Daum
}

Published online: 28 June 2014

(C) Springer Science + Business Media New York 2014

\begin{abstract}
Vaccines have saved the lives of innumerable children from infectious diseases. In the United States, state mandates for school immunization requirements and federal funding have enabled high immunization coverage and have resulted in historic low levels of many infectious diseases. However, in recent years, there have been widespread outbreaks of a number of vaccine-preventable infectious diseases, including measles, mumps, and pertussis. Reasons for these resurgences vary and are complex. They include decreases in vaccination rates, waning immunity, changes in the vaccine, and changes in the pathogen.
\end{abstract}

Keywords Vaccine immunizations - Vaccine hesitancy . Vaccine safety $\cdot$ Vaccine-preventable disease $\cdot$ Outbreaks . Measles · Mumps · Pertussis · Pneumococcus

\section{Introduction}

In recent years, there have been outbreaks and a rising incidence of certain vaccine-preventable diseases (VPDs). In this review, we will discuss the development of vaccine programs in the US which enabled high vaccine coverage and reductions in VPDs, vaccine hesitancy which has

\section{R. Lynfield ( $\square)$}

Minnesota Department of Health, 625 Robert Street North, P.O. Box 64975, St. Paul, MN 55164, USA

e-mail: ruth.lynfield@state.mn.us

\section{R. S. Daum}

Section of Infectious Diseases, Department of Pediatrics, University of Chicago, 5841 South Maryland Avenue, MC 6054, Chicago, IL 60637-1470, USA

e-mail: rdaum@peds.bsd.uchicago.edu impacted vaccine coverage, and changes in the epidemiology of measles, mumps, pertussis, and invasive infections due to Streptococcus pneumoniae.

Infectious diseases were the leading causes of death among US children at the beginning of the twentieth century. Vaccines are credited with preventing an estimated 103 million cases of childhood diseases since 1924 [1••]. The decrease in morbidity from specific VPDs between the "prevaccine era" and 2010 is provided in Table 1. A recent analysis found that by vaccinating a US birth cohort with the currently recommended schedule (excluding influenza, meningococcal, and human papillomavirus vaccines), 20 million cases of disease and 42,000 deaths are prevented; this translates into approximately $\$ 13.5$ billion of direct cost savings and $\$ 68.8$ billion in societal cost savings [2]. The 2014 recommended childhood vaccine schedule includes 13 vaccines which aim to prevent 16 infectious diseases, including tetanus, diphtheria, pertussis, poliomyelitis, measles, mumps, rubella, varicella, influenza, and infections from hepatitis A virus, hepatitis B virus, Haemophilus influenzae type b (Hib), Streptococcus pneumoniae, Neisseria meningitidis, rotavirus, and human papillomavirus [3].

Several legislative initiatives enabled establishment of high rates of vaccination in children, which have facilitated development of herd immunity. In 1963, Section 317 of the Public Health Service Act provided a mechanism to support health department immunization activities. In 1977, a federal Childhood Immunization Initiative enabled a system to provide comprehensive immunization services. By 1980, all states had schoolentry immunization laws which promoted high coverage of certain vaccines at school entry. In 1993, a second Childhood Immunization Initiative was aimed at increasing vaccination rates in preschool-aged children. Also in 1993, the Vaccines for Children (VFC) program provided 
Table 1 Comparison of annual morbidity from vaccine-preventable diseases during the twentieth century and 2010

\begin{tabular}{llll}
\hline Disease & $\begin{array}{l}\text { Twentieth } \\
\text { century }^{\mathrm{a}}\end{array}$ & $2010^{\mathrm{b}}$ & $\begin{array}{l}\% \\
\text { Reduction }\end{array}$ \\
\hline Diphtheria & 21,053 & 0 & 100 \\
Hepatitis A & 117,333 & $8,493^{\mathrm{c}}$ & 93 \\
Hepatitis B, acute & 66,232 & $9,419^{\mathrm{c}}$ & 86 \\
Haemophilus influenzae type b & 20,000 & $240^{\mathrm{d}}$ & 99 \\
$\quad$ in children aged <5 years & & & \\
Measles & 530,217 & 63 & $>99$ \\
Mumps & 162,344 & 2,612 & 98 \\
Pertussis & 200,752 & 27,538 & 86 \\
Pneumococcus invasive & & & \\
$\quad$ All ages & 63,607 & $44,000^{\mathrm{e}}$ & 30 \\
$\quad<5$ years & 16,069 & $4,700^{\mathrm{e}}$ & 72 \\
Poliomyelitis, paralytic & 16,316 & 0 & 100 \\
Rotavirus, hospitalizations & $62,500^{\mathrm{f}}$ & $28,125^{\mathrm{c}}$ & 55 \\
Rubella & 47,745 & 5 & $>99$ \\
Congenital rubella syndrome & 152 & 0 & 100 \\
Smallpox & 29,005 & 0 & 100 \\
Tetanus & 580 & 26 & 96 \\
Varicella & $4,085,120$ & $408,572^{\mathrm{c}}$ & 90 \\
\hline
\end{tabular}

${ }^{a}$ Estimated annual average number of cases in the prevaccine era for each disease. Source Roush et al. [61]

b Source See reference [62]

c 2009 estimate

d 23 type b and 223 unknown serotype (among children $<5$ years of age)

e http:/www.cdc.gov/abcs/reports-findings/survreports/spneu09.html

${ }^{f}$ Source Cortese et al. [63]

Source Hinman et al. [4, p. 51]

funding for recommended vaccines for Medicaid eligible children, uninsured children, underinsured children if they received vaccines at a Federally Qualified Health Center, and American Indians/Alaskan Natives [4•].

Although these programs have resulted in high coverage at school entry (CDC estimates $95 \%$ for recommended vaccines [4•]), many children do not receive vaccinations on time. A study in Chicago, which examined vaccination records of more than 66,500 children completing kindergarten in 2001-2002, found that only $31 \%$ at 7 months of age and $59 \%$ at 36 months of age had received all recommended immunizations on time. In addition, there were significant racial disparities with $25 \%$ of black children receiving vaccinations more than a year after the recommended age [5]. On-time vaccination is important to protect children from VPDs.

Widespread use of vaccines has resulted in substantial decreases in certain infectious diseases. Notably, smallpox has been eradicated from the world; measles, rubella, and congenital rubella syndrome have been eliminated (this can include imported cases with limited local transmission, but no sustained endemic transmission) from the US; and poliomyelitis has been eliminated from most of the world. Hib, once the primary cause of meningitis and other invasive infections, is now rare in young children. However, there have been resurgences in certain VPDs. Vaccine refusal has contributed to VPD resurgence because of the vulnerability of unvaccinated children to VPDs and decreased herd immunity in a community where there are clusters of vaccine refusers. In addition, there are other factors involved in the resurgence of VPDs. We will discuss vaccine hesitancy and then examine specific examples of resurgences in VPDs.

\section{Vaccine Hesitancy and Vaccine Refusal}

There have been individuals reluctant to use vaccines since vaccines became available. The reluctance may stem from philosophic, religious, or vaccine safety concerns.

\section{Philosophic Concerns}

A philosophic concern refers to a personal belief opposing vaccination. Philosophic concerns can include alternative approaches to vaccines in preventing and controlling infectious diseases, or not wanting government interference in a child's care. Some parents cite philosophic concerns, but actually have concerns about vaccine safety, often related to a particular vaccine. A notable example of early organized philosophic opposition is the establishment of the Anti-Vaccination League, in response to the Vaccination Act of 1853 which made smallpox vaccine compulsory in London [6]. Anti-smallpox vaccination groups became popular in many countries during periods of low disease incidence, when people did not personally encounter smallpox and its resulting morbidity and mortality. Similarly, many who are vaccine hesitant today have generally not encountered VPDs and do not consider them to be a significant threat to their children [7]. Notably, increases in measles vaccine receipt and increases in "on time" receipt occurred during 1989 and 1990, when Chicago was experiencing a measles outbreak, although there was not a concurrent increase in DPT and polio vaccines [8]. States that have easy exemption policies have higher rates of vaccine exemption [9]. This suggests that some individuals may be swayed away from a philosophic exemption, if the process is arduous.

\section{Religious Concerns}

Religious concerns have been cited frequently as a reason to refuse vaccination. Notably, opposition is more often 
philosophic or related to vaccine safety concerns among members of a community that is organized around faith than conflict with specific theological principles of the faith $\left[10^{\bullet \bullet}\right.$. There are some exceptions, such as members of the Church of Christ, Scientist, who believe that disease is cured or prevented by prayer, and therefore, vaccines are not needed. Interestingly, the founder, Mary Baker Eddy, said "Rather than quarrel over vaccination, I recommend, if the law demand, that an individual submit to this process, that he obey the law, and then appeal to the gospel to save him from bad physical results [11]." Other churches, such as the Dutch Reformed Church, have members who are concerned that vaccines will make a person less dependent on God, although others view vaccines as a gift from God that should be used [12]. Many Amish and Mennonite communities view vaccines as components of the modern world, and therefore, do not readily accept them. However, during outbreaks of VPDs, district leaders have often accepted vaccination [10••]. Although in the first half of the twentieth century, Jehovah's Witnesses opposed immunizations, in the 1990s, they acknowledged the benefit of vaccination. There are several Christian groups that relay on "faith healing" for wellness, rather than medical forms of prevention and treatment. To support vaccination, doctrines from many religions call for preserving life, caring for others, and responsibility to the community [10••].

Religious concerns have included issues related to vaccine manufacture, specifically vaccines made in cell lines derived from aborted fetuses. The Roman Catholic Church determined that being immunized does not involve taking moral responsibility for the abortions which produced the cell lines; further, those abortions were not done with the objective of producing the cell lines. However, the Roman Catholic Church asked parents and clinicians to raise the concern of using fetal cell lines in vaccines to governments and vaccine manufacturers [13]. Similarly, the Roman Catholic Church has said it is permissible to use a vaccine with Rubella virus strain RA 27/3, which was derived from an infected fetus [13]. Porcine constituents (such as hydrolyzed trypsin or gelatin) in vaccines have been of concern to Jews and Muslims. Religious leaders have typically permitted these vaccines to be administered because the components have been transformed from the original swine origins, the minute qualities have been extensively diluted, and the vaccine is intended for a medicinal purpose, and thus is not subject to dietary restrictions. Further, the purpose is to save a life and there is not an alternative product [10••].

\section{Safety Concerns}

Safety concerns raised in the past 40 years have impacted specific vaccination programs, particularly in association with whole cell pertussis vaccine, measles, mumps and rubella vaccine (MMR), and the use of thimerosal. In 1974, a study suggested that there were neurologic complications associated with whole cell pertussis vaccine, and diphtheria, pertussis, tetanus (DPT) vaccine rates plummeted in the UK as a result of intensive media reporting [14]. Pertussis, which had previously been controlled due to widespread vaccination, returned in the form of large outbreaks in the UK. In 1982, a television documentary "DPT: Vaccine Roulette" resulted in extensive negative publicity for DPT in the US and consequently there was a rise in litigation from parents blaming DPT for a variety of neurologic syndromes. These lawsuits threatened the continued manufacture of vaccines. In response, Congress passed the National Childhood Vaccine Injury Act in 1986, which established a no-fault compensation program for individuals injured following receipt of a recommended vaccine. Whole cell pertussis vaccines were associated with fever, local tenderness, and occasionally febrile seizures. As a result of public concern, acellular pertussis vaccines, which have a much lower rate of fever and local reactions, were developed and replaced whole cell vaccine in the US in the 1990s [15]. Safety concerns have remained an issue for some parents. Notably, a recent case-control study encompassing more than 2 million children, found no evidence of an association between whole cell pertussis vaccine and the occurrence of encephalopathy [16].

In the late 1990s, Andrew Wakefield, a British gastroenterologist, proposed an association between measles vaccine and autism [17]. MMR coverage rates in the UK decreased from $>90 \%$ in 1995 to $80 \%$ in 2003 (with pockets of lower vaccine coverage). Large outbreaks of measles occurred in the UK as well as in multiple countries in Europe. The US Institute of Medicine (IOM) reviewed available published and unpublished epidemiologic studies and found no evidence of a causal relationship between MMR and autism [18]. In 2010, after findings from an inquiry done by the British Medical Council, the Lancet retracted Wakefield's article [19].

Thimerosal, an ethyl mercury-containing preservative, was thought to be a potential cause of mercury toxicity and autism in the late 1990s because of increased use of vaccines containing thimerosal (Hib and hepatitis B vaccines, in addition to DPT). The level of ethyl mercury during the first 6 months of life exceeded the US. Environmental protection agency's safety level for methyl mercury (a more toxic mercury salt) [4•]. As a precaution, in 1999, the Centers for Disease Control and Prevention (CDC) and American Academy of Pediatrics (AAP) recommended that manufacturers decrease thimerosal in vaccines [20]. Manufacturers responded by removing thimerosal or decreasing it to trace amounts in vaccines for young children, with the exception of some multi-dose vial formulations of 
inactivated influenza vaccine which contains small amounts $(0.01 \%)$ [21]. Subsequent studies have found no association between use of thimerosal in vaccines and autism [18, 22].

Some parents have concerns about the number of vaccines an infant receives, resulting in vaccines being given at different ages than those recommended by the Advisory Committee on Immunization Practices (ACIP). By using an alternate vaccination schedule, children may not be protected from a VPD during a high risk age period. For example, a 20-month-old child in Minnesota, whose parents used a schedule that began vaccinations at age 5 years, developed invasive Hib disease (epiglottitis) at age 20 months (R. Lynfield, unpublished data). The IOM recently reviewed the childhood vaccination schedule and found no evidence of safety concerns specifically associated with the currently recommended childhood vaccine schedule [23].

There are resources to inform and persuade vaccine hesitant parents. It can be challenging to change the intent of a parent, as found in a recent study on providing information about MMR and measles using a variety of messages including textual information, images of diseases, and a narrative of a critical case of measles in an infant [24•]. Leask and colleagues have developed a framework and strategies to communicate with parents depending on the parental position [25**]. These authors promote building rapport, answering concerns, providing information, and facilitating valid consent. Resources for information on vaccine safety can be found on the websites of Children's Hospital of Philadelphia, AAP, and CDC [26-28]. Healthcare providers play a key role in dealing with vaccine hesitancy.

\section{Resurgences of Specific Vaccine-Preventable Diseases}

In this section, we discuss resurgences of measles, mumps, pertussis, and invasive pneumococcal disease that have occurred following periods of decreased incidence to illustrate the complexity of the problem.

\section{Measles}

Measles has been controlled by widespread vaccination. Measles vaccine was introduced in the US in 1963 and disease decreased dramatically from $>500,000$ reported cases and 500 deaths to 3,000 reported cases per year $[4 \cdot, 29]$. Measles virus is very transmissible and can be spread through the airborne route. The $\mathrm{R}_{0}$ or reproduction number (the average number of secondary cases produced by a primary case in a susceptible population) of measles virus is high- $15-17$ [30]. It is estimated that there is a $>90 \%$ chance of transmission to a susceptible individual after face-to-face contact [29]. In 1989-1991, the US experienced a resurgence of measles with 55,000 cases and 123 deaths [4•]. Cases occurred in high-school and college students who had a high level of coverage with a single dose of vaccine administered at 12-15 months of age. Because measles virus could cause infection and be transmitted in $2-5 \%$ of individuals who received a dose of vaccine but do not mount a primary immune response, the ACIP in 1989, recommended a routine second dose of MMR at 4-6 years of age [4•]. In the late 1980s, it was noted that many inner-city children, particularly belonging to racial and ethnic minorities, were not receiving MMR. This resulted in state and local immunization action plans to achieve $90 \%$ coverage of preschool children for vaccines recommended in the first 2 years of life. VFC provided the means to vaccinate many children, and by 1996 , racial and ethnic disparities significantly narrowed [31,32]. In 2000, elimination of endemic transmission of measles virus was achieved in the US [33].

According to CDC, an average of 60 cases of measles occurs each year in the US [34]. These cases are associated with importation of measles virus, although there may be limited local transmission if susceptible persons encounter the virus. Increased number of cases were observed in 2008 (140 cases), 2011 (220 cases), and 2013 (189 cases), and included outbreaks associated with unimmunized children who were old enough to receive vaccine, but whose parents declined vaccination [29]. For example, in 2011, 21 cases occurred in Hennepin County, Minnesota, linked to a 30-month-old unvaccinated child who acquired measles, while visiting Kenya [35]. Fourteen cases were hospitalized and over 3000 people were exposed. Sixteen cases were unvaccinated, seven of nine who were age eligible had parents with safety concerns. Six of these cases were of Somali descent (including the index case). Notably, MMR immunization rates had decreased to $54 \%$ among Somali children in Hennepin County associated with concerns about autism promoted by Andrew Wakefield, who made several visits to Minneapolis. In 2013, a large measles outbreak (58 cases) occurred in New York City in an Orthodox Jewish community [36]. The index case was an unimmunized 17-year old that had traveled to London. Infection spread in two neighborhoods in Brooklyn, and approximately 3,500 people were exposed. All cases were unimmunized, with 12 cases being too young for vaccine. Ensuring high levels of vaccination among individuals in a community can help prevent spread of imported measles cases.

\section{Mumps}

Mumps has also been controlled by widespread immunization. However, in contrast to the resurgence of measles, cases 
of mumps in the US appear to be due in large part to waning immunity, and periodic exposure to mumps virus. In 1967, live attenuated mumps vaccine was licensed. Prior to licensure, $>150,000$ reported cases occurred annually (incidence of $88 / 100,000$ ), this decreased to 5,270 cases (incidence of $2.5 / 100,000$ ) in 1982 [37]. Mumps virus is spread mainly via large droplets and the $\mathrm{R}_{0}$ is $10-12$ [30]. Beginning in late 1986 , a resurgence of mumps occurred with close to 13,000 cases reported in 1987 [37]. The resurgence was rapid and focal, with eight of the highest incidence states occurring in central, rural US states. The peak age of cases shifted from 5-9-year olds to 10-19-year olds. In 1989, ACIP recommended a second dose of measles vaccine for measles control, but because of concern about the resurgence of mumps, it was recommended that the dose to be given as MMR. In 1992 , the incidence of mumps decreased to $1.0 / 100,000$ and decreased further to $0.1 / 100,000$ (an average of 268 cases annually) in 2001-2005 [37].

In 2006, there was another rapid resurgence of mumps with 6,584 cases reported, again mostly occurring in rural, midwestern states [37]. The peak age shifted from 5-9-year olds to 18-24-year olds, many of whom were college students and 89-99\% had received 2 doses of vaccine (though most $>10$ years prior). In 2009-2010, outbreaks of mumps occurred in colleges and religious schools in northeastern US. A recent report described 3,502 outbreakrelated cases in New York and New Jersey in an Orthodox Jewish community [38]. Overrepresented were adolescent males, who had spent many hours in "intense face-to-face contact." Among 884 cases in children 13-17-years old, $89 \%$ had received two doses of MMR and $8 \%$ had one dose of MMR. In this outbreak, rates of orchitis were significantly higher in those who were not vaccinated versus those who received two doses of MMR (11 vs. $4 \%$, $p=0.04$ ) [38]. Notably, there have not been outbreaks among military populations, many of whom received a third dose of MMR as recruits [37]. Studying immunogenicity and long-term effectiveness of a third dose of mumps vaccine would be helpful in approaching the issue of waning immunity.

\section{Pertussis}

The epidemiology of pertussis is complex. There was an excellent response to whole cell pertussis vaccines, but in recent years cases have increased, particularly in the era of acellular pertussis vaccines. Whole cell pertussis vaccines became available in the US in the 1940s and the annual incidence of disease declined with widespread use of vaccine, from an average of $150 / 100,000$ population (150,000-260,000 cases with up to 9,000 deaths) prior to vaccine availability, to a nadir of $0.5 / 100,000$ (1,010 cases) in 1976 [15, 39, 40]. Bordetella pertussis is thought to spread mainly via the droplet route, but is very transmissible to those who are non-immune, with an $\mathrm{R}_{0}$ of $15-17$, and able to spread to $>80 \%$ of susceptible household contacts $[15,30]$. Interestingly, $B$. pertussis infection or immunization does not provide life-long immunity; recurrent infections (often not severe) occur, and immunity to whole cell vaccine is thought to wane after 5-10 years [15]. Due to concerns about reactions associated with whole cell vaccine (see "safety concerns" section), acellular pertussis vaccines were introduced in the US, replacing booster vaccine doses (age 15-18 months and age 4-6 years) in 1992 and primary series (ages 2, 4, 6 months) doses in 1997. There are three infant acellular pertussis vaccine formulations available in the US (containing 2, 3, or 5 pertussis antigens). In clinical trials, vaccine efficacy point estimates ranged from 80 to $85 \%$ with overlapping confidence intervals, suggesting that these vaccines are comparable in effectiveness [15].

Because of school-entry requirements, coverage with at least three doses of pertussis-containing vaccines has been high. However, the number of reported cases has risen. In 2004 , close to 26,000 cases of pertussis were reported. Notably, many of these cases occurred in adults (29\%) and adolescents (34\%) [41]. In 2006, ACIP recommended an additional dose of a pertussis-containing vaccine (Tdap -a different formulation than the infant diphtheria, pertussis, and tetanus vaccine) at age 11-12 years, and for adults including post-partum women [41, 42]. Infants are at the highest risk for severe pertussis including apnea, pneumonia, seizures, and encephalopathy. Approximately, $50 \%$ of infant cases are hospitalized and $1.6 \%$ of these infants die [43]. In 2011, in a further effort to protect infants, ACIP recommended Tdap for pregnant women and those in contact with young infants, and in 2012 ACIP updated guidance so that Tdap was recommended with each pregnancy $[44,45]$. It will be important to assess the effectiveness of this recommendation.

Large outbreaks of pertussis occurred in the US in 2010 (9,000 cases, 809 hospitalizations, and ten deaths in California alone), and the number of reported cases peaked in 2012, with $>48,000$ cases [46, 47]. Notably, since 2010 a new peak was observed in 7-10-year olds, and approximately $75 \%$ of these cases have been appropriately vaccinated. In 2012, a second peak was noted around age 13-14 years [47, 48•].

A number of factors have been suggested as contributing to the resurgence of pertussis, including waning vaccinerelated immunity, a less protective immune response from acellular vaccines compared with whole cell pertussis vaccines, and negligible impact of acellular vaccines on halting transmission of the bacterium. A case-control study in California found that the vaccine effectiveness of five doses of DTaP was $98 \%$ (95\% CI 96-99\%) within 12 months of 
vaccine, but decreased to $71 \%$ (95\% CI $46-85 \%$ ) by $\geq 60$ months after vaccine receipt [49•]. A case-control study with adolescents in Washington state, found that vaccine effectiveness of Tdap within 12 months was $75 \%$ (95\% CI 62-83\%), but waned to $41 \%$ (95\% CI 7-63\%) $\geq 2$ years post vaccination [50]. An Australian study found that children who received acellular vaccine (for at least the first dose of their primary series) were more likely to get pertussis than those who had received whole cell vaccine (either for first dose of their primary series or the entire series), suggesting that initial, priming antigens are important in eliciting an immune response, and that whole cell vaccines are more effective [51•]. A study from Oregon found that children primed with acellular vaccine had a higher rate of pertussis than those primed with whole cell vaccine [52•]. Animal model data indicate that whole cell vaccines elicit Th1 and Th17 responses, which may result in a more effective immune response to $B$. pertussis than the Th2 and Th17 responses elicited by acellular vaccines. Notably, addition of a Th1 promoting adjuvant to acellular vaccine alters the response to Th1 [53•]. Recent work has found that baboons immunized with acellular vaccine and exposed to $B$. pertussis can be colonized with $B$. pertussis and transmit infection, suggesting that acellular vaccine may not have a big impact on interrupting transmission [54•].

Another recent finding is that there has been a shift to predominately pertactin-negative strains among $B$. pertussis strains currently circulating in the US [55•]. Pertactin is a component in acellular vaccines, which is involved in attachment of the organism to epithelial cells. It is hypothesized that vaccine-induced antibody pressure has resulted in a predominance of pertactin-negative strains, although it is unknown if the vaccine effectiveness for these strains is different.

In addition to issues of changes in the immune response, waning of vaccine-induced immunity, lack of impact on transmission, and antigenic changes in the organism, some investigators have evaluated the role of vaccine refusal in pertussis resurgence. Omer and colleagues have found an association between geographic areas that had children with non-medical vaccine exemption and the occurrence of pertussis clusters, identifying a contribution of vaccine hesitancy in the complex picture of pertussis resurgence [56, 57]. In addition to maternal vaccination and ensuring high rates of vaccination, research resulting in more effective pertussis vaccines is an important step in addressing the resurgence of pertussis.

Invasive Disease Due to Streptococcus pneumoniae (Pneumococcus)

The epidemiology of invasive pneumococcal disease (IPD) reveals the enormous impact of widespread immunization of children with pneumococcal conjugate vaccine (PCV). However, a shift in the serotypes causing disease was observed a number of years after the introduction of the 7-valent PCV (PCV7). Prior to the licensure of PCV7 in 2000, an estimated 65,000 cases of IPD occurred each year in US children $<5$ years. The seven serotypes accounted for approximately $80 \%$ of IPD in young children, and within six years PCV-7 serotypes accounted for $2 \%$; overall IPD rates in this group decreased from 87.4/ 100,000 in 1999 to $20.8 / 100,000$ in 2004 [58, 59]. Decreased incidence was also observed in other age groups because colonized young children were a reservoir for pneumococcus, and PCV protected young children against colonization with the seven vaccine serotypes. However, within a few years, non-vaccine serotypes, particularly 19-A, began playing a bigger role in causing IPD. In 2010, a 13-valent PCV (PCV13) was licensed which included 19-A and five additional serotypes; these serotypes accounted for $63 \%$ of IPD in 2006-2007 in young children [58]. The incidence of IPD has again decreased and was $9 / 100,000$ in children $<5$ years in 2012 [59]. A recent study modeled potential changes in incidence of IPD by 2020, based on serotype changes occurring after widespread use of PCV13 [60॰]. It found that 170,000 cases would be prevented in all age groups from 2011 to 2020 with no serotype replacement, and 167,000 cases would be prevented if there was a replacement similar to that seen with 19A after PCV7. Although the model is promising for continued effective control of IPD with PCV13, it is important to track the serotypes causing IPD to ascertain potential changes that could herald an increase in incidence.

\section{Conclusions}

Vaccines have proven to be effective, safe, and valuable for ensuring children's health. Legislation has enabled all US children to have access to vaccines and has enabled high levels of vaccine coverage. Resurgence of certain VPDs has been experienced in recent years and occurs for a number of reasons including decreases in vaccine coverage, waning immunity in an individual, changes in the vaccine, and changes in the organism. Herd immunity has been threatened in geographic locations where there are pockets of multiple families refusing vaccine. Clinicians should understand the reasons for vaccine hesitancy and work with families to address their concerns about vaccines. Careful surveillance is needed to identify cases of VPD in order to understand the evolving epidemiology of these diseases post-vaccine licensure. Additional research to comprehend better the components of the immune response to different vaccines and the infections they 
prevent, and to develop more accurate correlates of protection is needed. We hope this additional research will enable a new generation of vaccines that can provide extended and effective protection against infectious diseases.

Disclosure Ruth Lynfield and Robert S. Daum declare that they have no conflict of interest.

Human and Animal Rights and Informed Consent This article does not contain any studies with human or animal subjects performed by any of the authors.

\section{References}

Papers of particular interest, published recently, have been highlighted as:

- Of importance

•- Of major importance

1. • van Panhuis WG, Grefenstette J, Jung SY, Chok NS, Cross A, et al. Contagious diseases in the United States from 1888 to the present. N Engl J Med. 2013;369:2152-8. This group obtained and digitized weekly surveillance reports which they have made publicly available. They describe the quantitative reduction in infectious diseases between 1888 and 2011 with a focus on the impact of vaccination.

2. Zhou F, Shefer A, Wenger J, Messonnier M, Wang LY, et al. Economic evaluation of the routine childhood immunization program in the United States, 2009. Pediatrics. 2014;133:1-9.

3. Centers for Disease Control and Prevention. Immunization Schedules. http://www.cdc.gov/vaccines/schedules/hcp/childadolescent.html. Accessed 19 Feb 2014.

4. - Hinman AR, Orenstein WA, Schuchat A; Centers for Disease Control and Prevention. Vaccine-Preventable Diseases, Immunizations and MMWR-1961-2011. MMWR Morb Mortal Wkly Rep. 2011;60:49-57. This report provides an excellent review of vaccines, federal programs and changes in vaccine-preventable diseases.

5. Dominguez SR, Parrott JS, Lauderdale DS, Daum RS. On time immunization rates among children who enter Chicago public schools. Pediatrics. 2004;114:e74-7.

6. Porter D, Porter R. The politics of prevention: anti-vaccination and public health in nineteenth-century England. Med Hist. 1988;1988(32):231-52.

7. Kennedy AM, Brown CJ, Gust DA. Vaccine beliefs of parents who oppose compulsory vaccination. Public Health Rep. 2005;120:252-8.

8. Goldstein KP, Philipson TJ, Joo H, Daum RS. The effect of epidemic measles on immunization rates. JAMA. 1996;276:56-8.

9. Omer SB, Richard JL, Ward M, Bednarczyk RA. Vaccination policies and rates of exemption from immunization, 2005-2011. N Engl J Med. 2012;367:1170-1.

10. • Grabenstein JD. What the world's religions teach, applied to vaccines and immune globulins. Vaccine. 2013;31:2011-23. This is an outstanding and detailed review of religions and concerns about vaccines.

11. Eddy MB. The First Church of Christ, Scientist and Miscellany. Boston: Church of Christ Scientist; 1913. p. 219-20. www. mbeinstitute.org/PWIntro.htm. Accessed 23 Feb 2014.
12. Ruijs WL, Hautvast JL, van Ijzendoorn G, van Ansem WJ, van der Vleden $\mathrm{K}$, et al. How orthodox protestant parents decide on the vaccination of their children: a qualitative study. BMC Public Health. 2012;12:408.

13. The Vatican. Congregation for the Doctrine of the Faith. Regarding the Instruction Dignitas Personae. http://www.vatican. va/roman_curia/congregations/cfaith/documents/rc_con_cfaith_ doc_20081212_sintesi-dignitas-personae_en.html. Accessed 19 Feb 2014.

14. Kulenkampff M, Schwartzman JS, Wilson J. Neurological complications of pertussis inoculation. Arch Dis Child. 1974;49:46-9.

15. Centers for Disease Control and Prevention. Pinkbook: Pertussis Chapter. Epidemiology of Vaccine Preventable Diseases. http://www. cdc.gov/vaccines/pubs/pinkbook/pert.html. Accessed 20 Feb 2014.

16. Ray P, Hayward J, Michelson D, Lewis E, Schwalbe J, et al. Encephalopathy after whole-cell pertussis or measles vaccination lack of evidence for a causal association in a retrospective casecontrol study. Ped Infect Dis J. 2006;25:768-73.

17. Wakefield AJ, Murch SH, Anthony A, Linnell J, Casson DM, et al. Ileal-lymphoid-nodular hyperplasia, non-specific colitis, and pervasive developmental disorder in children. Lancet. 1998;351:637-41.

18. Institute of Medicine. Immunization Safety Review: Vaccines and Autism. 2004. National Academies Press, Washington DC.

19. Editors of the Lancet. Retraction Ileal-lymphoid nodular hyperplasia, non-specific colitis and pervasive developmental disorder in children. Lancet. 2010;375:445.

20. Centers for Disease Control and Prevention. Notice to Readers. Thimerosal in vaccines: a joint statement of the American Academy of Pediatrics and the Public Health Service. MMWR Morb Mortal Wkly Rep. 1999;48:563-5.

21. Food and Drug Administration. Vaccines, Blood and Biologics. Thimerosal in Vaccines. http://www.fda.gov/biologicsblood vaccines/safetyavailability/vaccinesafety/ucm096228. Accessed 18 Mar 2014.

22. Thompson WW, Price C, Goodson B. Early thimerosal exposure and neuropsychological outcomes at 7 to 10 years. New Engl J Med. 2007;357:1281-92.

23. Institute of Medicine. Childhood immunization schedule and safety: stakeholder concerns, scientific evidence, and future studies. Washington DC: National Academies Press; 2013.

24. - Nyhan B, Reifler J, Richey S, Freed GL. Effective messages in vaccine promotion: a randomized trial. Pediatrics. 2014;133:1-8. The study incorporates web-based surveys done pre and postinterventions on a nationally-representative sample to assess impact of a variety of interventions which provided information about measles, mumps and rubella vaccine.

25. •• Leask J, Kinnersley P, Jackson C, Cheater F, Bedford H, et al. Communicating with parents about vaccination: a framework for healthcare professionals. BMC Pediatrics. 2012;12:154. Review of the literature that identified parental attitudes towards vaccination and development of a framework that healthcare providers can use targeted to parental positions.

26. Children's Hospital of Philadelphia. Vaccine Education Center. http://www.chop.edu/service/vaccine-education-center/vaccinesafety/. Accessed 21 Feb 2014.

27. American Academy of Pediatrics. Immunization. http://www2. aap.org/immunization/families/safety.html. Accessed $21 \mathrm{Feb}$ 2014.

28. Centers for Disease Control and Prevention. Vaccines and immunizations. http://www.cdc.gov/vaccines/vac-gen/safety/default.htm. Accessed 21 Feb 2014.

29. Centers for Disease Control and Prevention. Pinkbook: Measles Chapter. Epidemiology of vaccine preventable diseases. http:// www.cdc.gov/vaccines/pubs/pinkbook/meas.html. Accessed 20 Feb 2014. 
30. Anderson RM, May RM. Immunsation and herd immunity. Lancet. 1990;335:641-5.

31. Orenstein W. The role of measles elimination in development of a national immunization program. Pediatr Infect Dis J. 2006;25:1093-101.

32. Centers for Disease Control and Prevention. Status report on Childhood Immunization Initiative: national, state and urban area vaccination coverage levels among children aged 19-35 months-United States. MMWR Morb Mortal Wkly Rep. 1996;46:657-64.

33. Katz SL, Hinman AR. Summary and conclusions: measles elimination meeting, 16-17 March 2000. J Infect Dis. 2004;189(suppl 1):S43-7.

34. Centers for Disease Control and Prevention. Measles Outbreaks. http://www.cdc.gov/measles/outbreaks.html. Accessed 22 Feb 2014.

35. Gahr P, DeVries AS, Wallace G, Miller C, Kenyon C, et al. An outbreak of measles in an undervaccinated community. Pediatrics. 2014;134:e220-8.

36. Centers for Disease Control and Prevention. Notes from the field: measles outbreak among members of a religious communityBrooklyn, New York, March-June 2013. MMWR Morb Mortal Wkly Rep. 2013;62:752-3.

37. Barskey AE, Glasser JW, LeBaron CW. Mumps resurgence in the United States: a historical perspective on unexpected elements. Vaccine. 2009;27:6186-95.

38. Barskey AE, Schulte C, Rosen JB, Handschur EF, Rausch-Phung $\mathrm{E}$, et al. Mumps outbreak in orthodox Jewish communities in the United States. N Engl J Med. 2012;367:1704-13.

39. Centers for Disease Control and Prevention. Pertussis: surveillance and reporting. http://www.cdc.gov/pertussis/surv-reporting. html. Accessed 22 February 2014.

40. Centers for Disease Control and Prevention. Vaccines: Vac-Gen/ what would happen if we stopped vaccinations. Pertussis. http:// www.cdc.gov/vaccines/vac-gen/whatifstop.htm\#pertussis. Accessed 1 Apr 2014.

41. Centers for Disease Control and Prevention. Preventing tetanus, diphtheria and pertussis among adolescents: use of tetanus toxoid, reduced diphtheria toxoid and acellular pertussis vaccine, recommendations of the Advisory Committee on Immunization Practices. MMWR Morb Mortal Wkly Rep. 2006;55(RR03): $1-34$.

42. Centers for Disease Control and Prevention. Preventing tetanus, diphtheria and pertussis among adults: use of tetanus toxoid, reduced diphtheria toxoid and acellular pertussis vaccine, recommendations of the Advisory Committee on Immunization Practices supported by the Healthcare Infection Control Practices Advisory Committee (HICPAC), for use of Tdap among health-care personnel. MMWR Morb Mortal Wkly Rep. 2006;55(RR17):1-33.

43. Centers for Disease Control and Prevention. Pertussis (whooping cough). http://www.cdc.gov/pertussis/about/complications.html. Accessed 22 Feb 2014.

44. Centers for Disease Control and Prevention. Updated recommendations for use of tetanus toxoid, reduced diphtheria toxoid and acellular pertussis (Tdap) vaccine in pregnant women and persons who have or anticipate having close contact with an infant aged less than 12 months-Advisory Committee on Immunization Practices, 2011. MMWR Morb Mortal Wkly Rep. 2011;60:1424-6.

45. Centers for Disease Control and Prevention. Updated recommendations for use of tetanus toxoid, reduced diphtheria toxoid and acellular pertussis (Tdap) vaccine in pregnant women Advisory Committee on Immunization Practices, 2012. Morb Mortal Wkly Rep. 2013;62:131-5.

46. Winter K, Harriman K, Zipprich J, Schechter R, Talarico J, Watt J, Chavez G. California pertussis epidemic, 2010. J Peds. 2012;161:1091-6.
47. Centers for Disease Control and Prevention. Pertussis: Outbreak trends. http://www.cdc.gov/pertussis/outbreaks/trends.html. Accessed $22 \mathrm{Feb} 2014$.

48. - Clark TA. Changing pertussis epidemiology: everything old is new again. J Infect Dis. 2014;209:978-81. This paper provides a timely review of the epidemiology of pertussis in the United States.

49. - Misegades LK, Winter K, Harriman K, Talarico J, Messonnier $\mathrm{NE}$, et al. Association of childhood pertussis with receipt of 5 doses of pertussis vaccine by time since last dose, California, 2010. JAMA. 2012;308:2126-32. This is a well done and informative case-control study which evaluates the vaccine effectiveness of DTaP.

50. Acosta AM, Debolt C, Tesslimi A, Lewis M, Stewart L, et al. Vaccine effectiveness and duration of protection of tetanus toxoid, reduced diphtheria toxoid and acellular pertussis among adolescents, Washington State, 2012. Poster session abstract 139. ID Week, October 2-6, 2013, San Francisco.

51. - Sheridan SL, Ware RS, Grimwood K, Lambert SB. Number and order of whole cell pertussis vaccines in infancy and disease protection. JAMA. 2012;308:454-56. Using the Queensland, Australia vaccine registry linked with cases of pertussis, these investigators determined that children who received acellular pertussis vaccine for their primary course had higher rates of pertussis than those who received whole cell vaccine. If the primary course was mixed, rates of pertussis were highest for those who received acellular pertussis vaccine for the first dose.

52. - Liko J, Robinson SG, Cieslak PR. Priming with whole-cell versus acellular pertussis vaccines. New Eng J Med. 2013; 368:581-2. This group looked at immunization records from the Oregon immunization information system. Similarly, rates of pertussis were higher in those that received acellular vaccine for their first dose.

53. - Ross PJ, Sutton CE, Higgins S, Allen AC, Walsh K. Relative contribution of Th1 and Th17 cells in adaptive immunity to Bordetella pertussis: towards the rational design of an improved acellular pertussis vaccine. PLoS Path. 2013;(4):e1003264. This paper provides a comprehensive discussion of the immune response to pertussis vaccine, and suggested approaches towards an improved acellular pertussis vaccine.

54. - Warfel JM, Zimmerman LI, Merkel TJ. Acellular pertussis vaccines protect against disease but fail to prevent infection and transmission in a nonhuman primate model. Proc Natl Acad Sci USA. 2014;111:787-92. These investigators use an innovative model to understand response to exposure to B. pertussis after vaccination with acellular vaccine.

55. • Pawloski LC, Queenan AM, Cassiday PK, Lynch AS, Harrison $\mathrm{M}$, et al. Prevalence and molecular characterization of pertactindeficient Bordetella pertussis in the US. Clin Vaccine Immunolog. 2014;21:119-25. Screening of 1300 B. pertussis isolates from the US in the CDC collection dating back to 1935. Pertactin deficient isolates encompassed $>50 \%$ of isolates screened in 2012.

56. Omer SB, Kyle SE, Moulton LH, Halsey NA, Stokley S, et al. Geographic clustering of nonmedical exemptions to school immunization requirements and associations with geographic clustering of pertussis. Am J Epidemiol. 2008;168:1389-96.

57. Atwell JE, Van Otterloo J, Zipprich J, Winter K, Harriman K, et al. Nonmedical vaccine exemptions and pertussis in California, 2010. Pediatrics. 2013;132:624-30.

58. Pilshvili T, Lexau C, Farley MM, Hadler J, Harrison LH, et al. Active Bacterial Core Surveillance/Emerging Infections Program Network. Sustained Reductions in invasive pneumococcal disease in the era of conjugate vaccine. J Infect Dis. 2010;201:32-41.

59. Centers for Disease Control and Prevention. Active Bacterial Core Surveillance Main Page. http://www.cdc.gov/abcs/reportsfindings/surv-reports.html. Accessed 20 Feb 2014. 
60. - Link-Gelles R, Taylor T, Moore, Active Bacterial Core Surveillance. Forecasting invasive pneumococcal disease trends after the introduction of 13-valent pneumococcal conjugate vaccine in the United States, 2010-2020. Vaccine. 2013;31:2572-7. This paper models the number of invasive pneumococcal cases during the ten years post-licensure of 13-valent pneumococcal conjugate vaccine.

61. Roush SW, Murphy TV, Vaccine-Preventable Disease Table Working Group. Historical comparisons of morbidity and mortality for vaccine-preventable diseases in the United States. JAMA. 2007;298:2155-63.

62. Centers for Disease Control and Prevention. Final 2010 reports of nationally notifiable infectious diseases. MMWR Morb Mortal Wkly Rep. 2011;60(32):1088-101.

63. Centers for Disease Control and Prevention. Prevention of rotavirus gastroenteritis among infants and children: recommendations of the Advisory Committee on Immunization Practices (ACIP). MMWR Morb Mortal Wkly Rep. 2009;58(RR-02):1-25. 